\title{
Fetal development of regulatory mechanisms for body fluid homeostasis
}

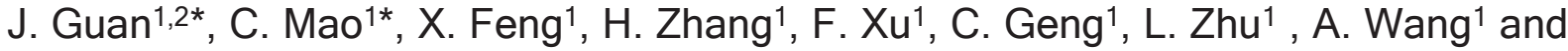 \\ Z. $\mathrm{Xu}^{1,3}$
}

${ }^{1}$ Perinatal Biology Center, Soochow University School of Medicine, Suzhou, China

2Department of Microbiology, Bengbu Medical College, Bengbu, Anhui, China

${ }^{3}$ Center for Perinatal Biology, Loma Linda University School of Medicine, Loma Linda, CA, USA

Correspondence to: Z. Xu, Perinatal Research Laboratory, Soochow University School of Medicine, Suzhou, China or Center for Perinatal Biology, Loma Linda University School of Medicine, Loma Linda, CA 92350, USA

E-mail: zxu@llu.edu

The balance of body fluids is critical to health and the development of diseases. Although quite a few review papers have shown that several mechanisms, including hormonal and behavioral regulation, play an important role in body fluid homeostasis in adults, there is limited information on the development of regulatory mechanisms for fetal body fluid balance. Hormonal, renal, and behavioral control of body fluids function to some extent in utero. Hormonal mechanisms including the renin-angiotensin system, aldosterone, and vasopressin are involved in modifying fetal renal excretion, reabsorption of sodium and water, and regulation of vascular volume. In utero behavioral changes, such as fetal swallowing, have been suggested to be early functional development in response to dipsogens. Since diseases, such as hypertension, can be traced to fetal origin, it is important to understand the development of fetal regulatory mechanisms for body fluid homeostasis in this early stage of life. This review focuses on fetal hormonal, behavioral, and renal development related to regulation of body fluids in utero.

Key words: Fetal body fluids; Fetal hormonal regulation; Fetal renal regulation; Swallowing

Research partially supported by the National Natural Science Foundation (\#30570915), Jiangsu Natural Science Key Grant (BK2006703), Suzhou Key Lab Grant (SZS0602), Suzhou International Scientific Cooperation Grant (SWH0716), and Suda Medical Development Key Grant for C. Mao.

*These authors contributed equally to this study.

Received January 10, 2008. Accepted 14 April, 2008

\section{Introduction}

Water and sodium are the two major determinants of body fluid homeostasis. Water accounts for approximately $60 \%$ of body weight, with two-thirds of body water within cells and one-third in interstitial spaces and plasma. Addition (through ingestion) or loss (through excretion, salivary loss, respiration, perspiration, etc.) of either water or sodium to/from the body alters not only net fluid balance but also osmotic equilibrium, thereby changing the relative distribution of fluids between the compartments. Reflex, behavioral, and hormonal responses are three essential routes to correct water and sodium imbalances and main- tain body fluid homeostasis. Reflex and hormonal mechanisms employ the autonomic nervous system and endocrine responses to modify renal losses of sodium and water in states of dehydration, and to regulate vascular volume. Behavioral responses include thirst, water and salt intake. There have been several excellent reviews $(1,2)$ regarding body fluid homeostasis. However, these reviews focused on matured regulatory mechanisms in adults for body fluid homeostasis. In this article, we pay special attention to the development of regulatory mechanisms during the early life stage-fetal periods. Notably, a large number of reports in the last two decades strongly support the "Barker theory" (3), and it is known that prena- 
tal factors can cause imprinting with long-term influence after birth, and many diseases such as hypertension and type II diabetes can be "programmed" in fetal origin (4). Thus, it is of great importance to understand the regulatory mechanism for body fluid balance at early developmental stages. In this review, we have focused on the hormonal, renal, and behavioral regulation of body fluids at fetal life in utero.

\section{Hormonal regulation of fluid homeostasis}

\section{Fetal renin-angiotensin system}

Angiotensin precursors, enzymes, and products in the fetus. The classic renin-angiotensin system (RAS) consists of blood-borne renin released from the kidney, which acts on angiotensinogen (AGT) synthesized predominantly in the liver to produce angiotensin I. A dipeptide is released to produce the octopeptide angiotensin II (Ang II) by an enzyme, angiotensin-converting enzyme (ACE) present in the vasculature, particularly in the lung. Ang II generated in the systemic circulation then acts as an endocrine hormone causing biological effects by binding to specific high affinity receptors (at least two subtypes of Ang receptors: AT1 and AT2). All components of RAS (AGT, renin, ACE, AT1 and AT2) are expressed from early gestation in humans (5) and animals (6).

The expression of AGT gene can be detected at early gestation in human fetal liver and kidney (5) and at midgestation in cord blood (7), and AGT protein products can be identified in the fetus. Fetal plasma AGT levels are greater at late gestation than at early gestation, indicating that RAS-mediated regulation in the fetus is dependent on the gestational period. Renin-containing cells have been demonstrated in the walls of renal interlobar and afferent vessels by 44 days of gestation (term: 145 days) in fetal sheep. By $90-100$ days of gestation, renin is localized closer to the glomerulus, while after 131 days of gestation renin-containing cells are distributed predominantly in the afferent glomerular vessels (8). Studies from three different models (individual isolated cells, organ slice, and whole animals) suggest that renin secretion is greater in the ovine fetus close to term than at earlier gestation (9). These studies suggest that there is an age-dependent increase in fetal renin in the lamb with an increase in the number of renin-containing cells and the renin content per cell in the kidney. The mRNA for ACE can be detected in a number of fetal tissues, including the heart, liver, lung, and brain in the early gestation period, and ACE is also present in human and ovine mesonephros and the metanephros (5).

One of the major roles of Ang II in the fetus is to maintain a high urine flow and thus ensure adequate volume of fetal fluids (amniotic and allantoic in sheep). When Ang II is infused into the fetus there is an increase in urine flow and sodium excretion rates. In addition, elevated levels of Ang II in the fetus can increase blood pressure and cause diuresis at least from midgestation (10). Intracerebroventricular (icv) injection of Ang II (11) elicits pressor responses in the near-term ovine fetus and results in compulsive drinking, and hormone release.

Chronic increases in fetal plasma Ang II suppress the secretion of prorenin and renin in the fetal sheep kidney (12). The chronic infusion of enalaprilat (ACE inhibitor) inhibits fetal AGT in both early and late gestation. Thyroid hormone and the renal nerves can regulate RAS activity and both AT1 and AT2 receptor mRNA and protein expression $(13,14)$ in the fetus.

In addition to its well-known roles in blood pressure regulation and sodium/water homeostasis, Ang II also acts as a growth factor and cytokine. There is growing evidence that Ang II may play a role during the development of the placenta and fetal growth (15).

Fetal angiotensin receptors. Ang II as the main active peptide of RAS acts at specific G-protein-coupled receptors, AT1 and AT2. Several lines of evidence suggest that fundamental differences exist in expression and localization of both AT1 and AT2 receptors in the fetus. The expression of AT1 mRNA (5) is present in the fetus much earlier: at 27 days of gestation in ewe adrenal gland, at 8 weeks in human neocortex, and at embryonic day 17 in rat adrenal gland; whereas AT2 mRNA was detected as early as AT1 mRNA in the ovine fetus, at 5-6 weeks in the human fetus, and at embryonic day 15 in rat fetus. Furthermore, changes in AT1 and AT2 expression (16) are opposite. The level of AT1 is low in early gestation, before rising to a plateau and then increasing significantly close to term. AT2 expression, on the other hand, is highest at midgestation and decreases thereafter. The mechanisms underlying these ontogenic patterns of expression are not known.

The central angiotensin receptors are well developed and established in the last trimester of gestation. Both AT1 and AT2 receptors have appeared in the major structures in the angiotensin-related central cardiovascular and body fluid controlling pathways at the 0.7 of the gestational age (17). Utilizing the in situ hybridization technique, AT1 receptor mRNA subtype appears in late gestation at embryonic day 19 (E19) in forebrain areas involved in fluid homeostasis and cardiovascular regulation in rodents. AT2 receptor mRNA appears earlier at E13 and is strongly but transiently expressed in structures involved mainly in motor functions and sensory integration. The appearance of the brain receptors indicates the importance of the role 
angiotensin plays in the maintenance of fetal physiological functions, including cardiovascular and body fluid balance. The questions whether AT1 and AT2 receptors are co-localized at the cellular level and which mechanisms mediate a possible AT1-AT2 receptor crosstalk still remain to be resolved.

Most of Ang II-induced physiological responses appear to be mediated by AT1 receptors. Endogenous Ang II, via activation of central AT1 receptors, exerts hypertensive effects under normal conditions in the near-term ovine fetus. AT2 receptors do not appear to be involved, because icv injection of PD123319, the specific antagonist of AT2 receptor, did not affect Ang II-induced cardiovascular effects. This indicates that the central RAS and AT1, but not AT2 receptor, are critically involved in the regulation of arterial pressure in the near-term fetal sheep (18). In the near-term ovine fetus, AT1 receptors but not AT2 receptors (19) contribute to dipsogenic and pressor responses, as well as arginine vasopressin (AVP) release. Although little is known about the role of the AT2 receptor in the regulation of cardiovascular functions and body fluid balance, the high expression of AT2 receptors during fetal and early postnatal life implies an important role in cellular differentiation and organ development. Experiments using specific agonists and antagonists have provided new evidence for the involvement of AT2 receptors in the regulation of growth, cell proliferation, and apoptosis. More interestingly, the AT2 receptor has been shown to be reexpressed in the adult animal after cardiac and vascular injury or during wound healing, suggesting a role for this receptor in tissue remodeling, growth, or development. Recent and concordant data suggested (20) that overstimulation of AT2 receptors might be involved in cardiac and vascular hypertrophic processes, indicating that AT2 receptor may be involved in pathological processes in some diseases. In light of this, these chronic changes may also cause functional changes in body fluid regulation.

Recent studies have shown that components of the RAS are candidates for a genetic link between low birth weight and adult diseases. Several genes from RAS have been found to be associated with cardiovascular diseases and insulin resistance after birth $(14,15)$. This suggests that RAS may play an important role in the development of cardiovascular diseases and diabetes in fetal origin. Therefore, it should be interesting to test whether and to what extent the mediation by RAS mechanisms of body fluid regulation is different in these experimental models.

\section{Fetal aldosterone}

The ovine fetal adrenal gland $(21,22)$ is capable of secreting aldosterone as early as about 40 days of gestation, and plasma aldosterone concentrations over the last trimester of gestation are equal to or greater than levels present in maternal circulation. Under physiological conditions, adrenocorticotropic hormone (ACTH) can stimulate aldosterone production during middle gestation in the ovine fetus. In both sheep and primates, secretion of aldosterone by the fetal adrenal gland is low during most of gestation, and only small increases are induced by stress or infusion of ACTH. Although aldosterone concentrations in the fetus are increased during stress, the usual stimuli of aldosterone production are not able to produce consistent increases in aldosterone concentrations in the fetus in vivo.

Blockade of the AT2 receptor (23), however, enables Ang II to stimulate aldosterone. This suggests that the inability of Ang II to stimulate aldosterone may be due in part to Ang II binding to the AT2 receptor and limiting the amount of Ang II available and/or antagonizing the effects of Ang II on the AT1 receptor. This suggestion is supported by the fact that in ovine fetuses more than 110 days of age, plasma aldosterone can be stimulated by Ang II, but high doses are required to produce moderate changes.

In the near-term ovine fetus, aldosterone can alter fetal urine electrolyte excretion, decreasing urinary sodium excretion and increasing potassium excretion (24), in response to intravenous aldosterone administration. Moreover, the amount of urinary sodium reabsorbed is regulated partly by aldosterone, which is physiologically active and induces increased urinary sodium reabsorption. Meanwhile in late-gestation pregnant sheep, intra-amniotic aldosterone can be absorbed into the fetal circulation (24), and subsequently alter fetal urine composition. Fetal urine sodium excretion is significantly decreased and potassium excretion increased, although there is no change in urine flow rate or fetal plasma electrolytes. When fetuses were adrenalectomized at 120 days of gestation, removing the endogenous source of cortisol and aldosterone, the rate of fetal urine production and its composition are normal up to 140 days (25). Together, the data suggest: 1) ACTH- and Ang II-mediated aldosterone production is relatively weaker in fetuses than in adults, indicating that these regulatory mechanisms in fetuses are immature; 2) both intra-amniotic and fetal aldosterone in circulation play a partial role in renal excretion in body fluid regulation in the fetus.

\section{Fetal natriuretic peptides}

Atrial natriuretic peptide (ANP), brain natriuretic peptide (BNP) and C-type natriuretic peptide (CNP) belong to a family of hormones that have diuretic, natriuretic, and vasodepressor activities in maintaining blood pressure 
and fluid homeostasis in adults. Proteins of natriuretic peptides and their mRNA can be detected during embryogenesis at early developmental stages. During embryogenesis in mice, ANP and BNP mRNA appear at around 89 days of gestation with a peak at 12.5 days (26). No CNP expression has been detected in developing hearts of either mouse or human embryos $(26,27)$. During development, higher levels of ANP mRNA expression (26) and ANP protein were detected in ventricles than atria in rodents. Conversely in fetal sheep, both of these are greater in the atria than ventricles throughout gestation (28). However, in human fetal ventricles, ANP mRNA is considerably higher than that in adult ventricles and tends to decrease with gestational age (27). Peptide levels of ANP and BNP in fetal ventricles have also been reported to be higher than those in the adult ventricle. In general, these studies indicate that the relative contribution of ventricular ANP is significantly greater in the embryo than in the adult, and in some species the ventricle is the predominant site of ANP and BNP expression during in utero development.

As reported by Walther et al. (29), the natriuretic peptides appear to respond to similar stimuli, and to perform similar cardiovascular functions during development as they do in adults. The fetal natriuretic peptides $(30,31)$ can react to volume loading, hyperosmolality, and vasoconstrictors Ang II, phenylephrine, and endothelin in a manner similar to that in the adult heart; however, ANP and BNP respond differently to short-term and long-term volume load in the fetal circulation (32). Fetuses with Rhesus isoimmunization, and therefore long-term overload, exhibited significantly higher concentrations of ANP, whereas BNP was not influenced. In contrast, a short-term volume load by intravascular transfusion led only to a significant increase in BNP. Furthermore, infusion of ANP into the circulation of fetal sheep, albeit at supraphysiological concentrations (increasing plasma levels from 163 to $>2000$ $\mathrm{pg} / \mathrm{mL}$ ), decreased arterial blood pressure, and elicited diuresis but not natriuresis (30). Therefore, the natriuretic peptide system appears to be functional by midgestation, to respond to volume change, and to regulate blood pressure and body fluid balance in the developing embryo.

The natriuretic peptides can also act as vasodilators in the fetal-placental vasculature, regulating the blood supply to the fetus, as demonstrated by expression of BNP and CNP in the mouse placenta (26), and expression of ANP in the human placenta by cytotrophoblast cells (33). Furthermore, ANP and BNP administered into the fetal placental circulation have been shown to inhibit the effect of vasoconstrictor agents.

Both ANP and BNP exert their biological actions by binding to the natriuretic peptide receptor (NPR)-A, result- ing in the generation of the second messenger cGMP, while CNP binds natriuretic peptide receptor (NPR)-B with high affinity. It is known that there are three different natriuretic peptide-specific cell surface receptor proteins: NPRA, NPRB, and NPRC. They are also known as NPR1, NPR2, and NPR3, or as GC-A, GC-B, and the clearance receptor, respectively, because both NPRA and NPRB contain guanylyl cyclase (GC) catalytic activity. However, NPRC functions without GC activity. To date, knowledge about the natriuretic peptide receptor in fetuses is limited (34). Expression of the GC-A receptor has been detected in the ovine fetal kidney and the vascular system. In contrast to ANP and BNP, CNP is unable to stimulate the production of cGMP in bovine embryonic aortic endothelial cells, but CNP is the most effective of the three peptides with respect to the stimulation of CGMP in fetal human vascular smooth muscle cells. Therefore, the GC-A receptor seems to be expressed in embryonic endothelial cells, whereas GC-B is located in the cell membrane of fetal smooth muscle cells. The binding was partly inhibited by excess of the ring-deleted ANP analogue, ANP(4-23) - a clearance receptor-specific peptide - indicating the presence and function of the third natriuretic peptide receptor. In the lungs of newborn piglets (35), ANP binds more strongly in veins than in arteries, indicating the presence of the GC-A receptor during maturation of the lung.

\section{Fetal vasopressin and oxytocin}

AVP and oxytocin (OT) are small nonapeptide hormones that differ in only two of nine amino acids. AVPexpressing neurons have not been observed until 26 weeks of gestation in the human fetal suprachiasmatic nucleus (36). In the central nervous system (37), the genes for rodent AVP and OT appear as early as day 16 of intrauterine life. AVP transcripts were detected by in situ hybridization on day 16 in the supraoptic nucleus, and on day 21 in the hypothalamic suprachiasmatic nucleus in rodents. OT prohormone is not detected before day 16, while mature OT levels are low during gestation in rodents, and synthesis of OT is first detected by immunohistochemistry on the second day of postnatal life in rodents. In the murine fetal thymus, vasopressin (VP) transcription was detected on day 14-15, while OT transcripts (38) were detected by RTPCR as early as day 13. This indicates that VP and OT appear in the central nervous system at different stages of gestation. This difference in appearance in the brain suggests a difference in translation and precursor processing between hypothalamic neurons and thymic epithelial cells. Such discrepancy concerns the last enzyme in the processing of neurohypophysial peptides, peptidyl-glycine, 
an amidating monooxygenase, which is present in an active form in thymic epithelial cells (39). Among all animals, AVP mRNA expression was significantly negatively correlated with pituitary AVP content. Several studies $(40,41)$ suggest that a dynamic AVP synthesis-content feedback relationship is functioning in the near-term fetus. Arnauld et al. (40) reported that 5 days of dehydration depleted rat pituitary glands of 90 to $95 \%$ of their AVP content and induced a 2-fold increase in AVP mRNA. During rehydration, pituitary AVP content gradually increased and hypothalamic AVP mRNA gradually decreased. Furthermore, the prolonged prenatal exposure to plasma hypertonicity may imprint the hypothalamic-pituitary AVP regulatory system (41).

Three VP receptors have been characterized. V1a (vascular/hepatic) and $\mathrm{V} 1 \mathrm{~b}$ (anterior pituitary) receptors are selectively coupled to the $\mathrm{G} q / 11$ family, mediating the activation of distinct isoforms of phospholipase $C ß$, and resulting in the breakdown of phosphoinositide lipids. The third VP receptor (V2, kidney), on the other hand, is coupled to Gs (42), resulting in the activation of adenylate cyclase. AVP receptors are observed first in the ventral pontine reticular formation of the rat on day 16 of gestation. Comparison between receptor distribution in infant and adult rat brain by in vitro autoradiography shows that in some areas (e.g., zona incerta, dorsal raphe, locus coereleus, spinal trigeminal nucleus, and the gray matter of the spinal cord) the receptors decrease progressively with development. While OT appears to have only one form of receptor, several lines of evidence (43) show that the oxytocin receptor plays a key role in mammalian reproduction as well as other physiological responses such as cardiovascular homeostasis.

Though AVP and OT only differ by two amino acids, the physiological actions of AVP are completely different from those of OT. AVP plays a role in the kidney, blood vessels, lung, and motor activity. AVP increases the water permeability of the collecting duct via $\mathrm{V} 2$ receptors. The binding of AVP to the V2 receptor can induce the translocation of aquaporin from a store in intracellular vesicles to the apical plasma membrane of the principal cells in the collecting duct (44). This effect is mediated by cAMP production in the basolateral membrane of the principal cells. In addition, AVP is absorbed rapidly across the intramembranous route from the amniotic cavity into the fetal circulation resulting in fetal antidiuresis. AVP has important effects on vascular tone via $\mathrm{V} 1 \mathrm{a}$ receptors. In fetal and newborn sheep, high plasma AVP increased resting levels of mean arterial blood pressure, and decreased renal sympathetic nerve activity and heart rate. Contrary to adults, circulating AVP does not modulate the arterial baroreflex in fetal and newborn sheep. Circulating VP had no effect on cerebral blood flow because VP in the peripheral circulation does not readily cross the blood-brain barrier. In near-term ovine fetuses, an intravenous injection of AVP inhibited fetal lung fluid production, and this effect on lung fluid is likely mediated by the V1 receptor, not the V2 receptor (45). On embryonic day 20 in rats, the central (intracisternal) administration of AVP caused a 4-fold increase in fetal motor activity, including the uncommon patterns of mouthing, licking, and facial wiping (46). V1 receptor-containing neurons in rostral and caudal regions in the brain regulate perioral responsiveness. Blockade of caudal V1 receptors or activation of rostral V1 receptors reduces fetal responsiveness to perioral cutaneous stimulation. Activation of caudal $\mathrm{V} 1$ receptors or blockade of rostral V1 receptors increases fetal responsiveness to perioral stimulation, including oral capture and grasping of an artificial nipple. Recent studies (47) have demonstrated that central administration of Ang II can induce an increase in plasma AVP in the ovine fetus from pre-term to near-term. The increase in plasma AVP was associated with an increase in activation of AVP-neurons marked with c-fos expression in the hypothalamic structures, and the $\mathrm{V} 1$, not the $\mathrm{V} 2$ receptor mechanism mediates central Ang II-induced fetal cardiovascular changes.

\section{Fetal renal regulation}

Studies in late-gestation pregnant sheep demonstrated that maternal volume loading or dehydration did not result in changes in fetal blood volume. Fetuses maintain blood volume by reducing the lung fluid and urine production despite attenuation in maternal blood volume (48). In contrast, renal regulation is important in body fluid balance.

Kidney development in mammals involves the formation of a pronephros, mesonephros (the functional kidney in fish and amphibians) and finally the metanephric kidney, which form successively from the intermediate mesoderm in increasing complexity (49). The pronephros is not functional but is required for mesonephros formation, which will execute renal functions in the embryo. Later in development, the mesonephros will be replaced by the metanephros, the adult functional kidney. Formation of the metanephric kidney begins at gestational week 4 to 5 in humans, gestational day 27 in sheep, and embryonic day 10.5 in mice. The metanephric kidney develops from two distinct embryonic primordial precursors, the mesenchymal blastema and the epithelial cells of the ureteric bud. In fact, it is a two-step event. First, the ureteric bud is induced by the mesenchymal blastema to grow out from the mesonephric duct. The epithelium originating from the ureteric 
bud will give rise via branching morphogenesis to the ureter and the collecting ducts. Second, the mesenchymal blastema is induced by the invading ureter to undergo nephrogenesis to form the nephrons and glomeruli. Eventually, nephrons from glomerulus to distal tubule and collecting ducts fuse to form the complete uriniferous tubules.

With the development of the renal tissue, the function of renal regulation for body fluid is developmentally formed. The functional units of the metanephric kidney, the nephrons, consist of the glomeruli, the proximal and distal convoluted tubules and Henle's loop. In rats and mice, the first generation of nephrons becomes functional around birth while branching morphogenesis of the cortical collecting duct and tubulogenesis of the last nephron generation are completed around postnatal day 7 . In humans and large mammals such as sheep, nephrons become functional during gestational week 32-36 in humans (50), and formation of the uriniferous tubular system is completed before birth, e.g., in gestational week 37 in humans and around gestational day 135 in sheep. The fetal glomerular filtration rate increases rapidly as the number and size of nephrons increase. Renal blood flow changes during fetal life, reaching $20 \mathrm{~mL} / \mathrm{min}$ at 25 weeks of gestation and 60 $\mathrm{mL} / \mathrm{min}$ near term in humans (51). These data, together with the results of morphological studies, demonstrate a sequence of coordinated changes during renal development and maturation.

Meanwhile, transporters and channels also develop into nephrons and collecting duct. The rate of proximal tubule glucose transport and the transport of most other solutes is lower in the neonate than the adult, but this is not true of phosphate (52). In mice, the Na-K-2Cl cotransporter (NKCC2) (53) is expressed in the developing loop of Henle as early as 14.5 days of fetal age. Aquaporin 1 (AQP1), the water channel located on the apical and basolateral membranes of the proximal tubule, has no or little expression in rat fetal kidneys. It increases immediately before birth and continues to increase until about 2 weeks of life, when its expression is similar to that of the adult. Although the neonatal tubule has a much lower expression of AQP1, it can still transport water with a small osmotic gradient and has unexpectedly high osmotic water permeability. This is mainly attributable to neonatal tubule properties (54). First, the lipid membrane of the neonatal tubule is more fluid than the adult tubule and therefore a larger fraction of water can pass through the lipid bilayer. Secondly, the neonatal tubule cells have a smaller cell volume, and thus, the intracellular compartment provides less resistance for the movement of water. mRNA and protein levels of AQP2, which is the main target of AVP action in the collecting duct, were lower during early postnatal life, reaching maxi- mal expression at 10 weeks of age (55). These data suggest that renal epithelia gradually acquire the ability to transport water necessary for adult life.

Some humoral factors such as Ang II, AVP, and aldosterone can change the production of urine to regulate body fluid in the fetal kidney. Ang II modulates renal blood flow and glomerular filtration rate through renal vasoconstriction acting directly on AT receptors in glomerular and proximal tubular cells. In the fetus at late gestation, the reduction of the availability of Ang II by converting enzyme inhibitors decreases glomerular filtration rate and renal vascular resistance while increasing fetal renal blood flow, resulting in low to nonexistent urine flow (56), whereas infusion of Ang II decreases proximal tubule sodium reabsorption. Ovine fetuses of less than 112 gestational days had a diminished response to infusion of AVP compared with more than 112-day-old and older fetuses. The lower responsibility of immature kidney to AVP (57) may decrease water reabsorption in collecting duct and limit urine concentration. In brief, histological studies have demonstrated that fetal kidneys are relatively intact, and physiological experiments have shown that renal functions are relatively mature before birth. Thus, renal regulation in body fluid homeostasis actually appears in utero. To what extent this mechanism would be influenced by environmental factors during pregnancy is an interesting question that has attracted great attention.

\section{Fetal behavior regulation}

Swallowing develops in utero and contributes to fetal body fluid homeostasis and regulation of amniotic fluid volume. In ovine fetus, swallowing responses to dipsogenic stimuli (58-60) are intact and functional at near-term (0.85 gestation). Fetal swallowing occurs both spontaneously and by dipsogenic stimuli. Spontaneous fetal swallowing is approximately 43 times per hour, and the amount of amniotic fluids swallowed is $35 \mathrm{~mL} / \mathrm{h}$, about $840 \mathrm{~mL} /$ day. This volume, swallowed daily, of $100-300 \mathrm{~mL} / \mathrm{kg}$ body weight in the ovine fetus is markedly greater than the adult daily volume of $40-60 \mathrm{~mL} / \mathrm{kg}$. Furthermore, spontaneous fetal swallowing occurs at a significantly (6-fold) higher rate than spontaneous adult drinking activity after body weight differences are adjusted for. Several studies explored the neuronal mechanisms underlying the high rate of in utero fetal swallowing. In chronically prepared nearterm ovine fetuses, icv injection of Ang II or neuronal nitric oxide synthase (nNOS) blocker or N-methyl-D-aspartate (NMDA) receptor antagonists, which block either central Ang II receptors (19), nNOS, or NMDA receptors (58-60), markedly reduced spontaneous fetal swallowing. These 
results provide evidence that tonic activity of brain-derived Ang II, NMDA receptors, and nNOS contribute to the high rate of basal ovine fetal swallowing. It has been suggested that thirst is triggered by accumulation of presynaptic Ang II, releasing presynaptic glutamate, which binds to postsynaptic glutamate NMDA receptors with subsequent calcium influx, activation of nNOS, and nitric oxide release (58-60).

In utero dipsogenic stimuli such as dehydration (hypertonicity) (59) and central administration of Ang II (60) evoke swallowing responses in the fetus. Several studies suggest that there is an elevated fetal threshold for osmotic dipsogenic stimulation compared with that of the adult. In the adult sheep, water intake is stimulated in response to a $2 \%$ increase in plasma tonicity. However, the ovine fetus does not increase swallowing in response to a 3-5\% increase in osmolality, but requires up to a $10 \%$ increase in plasma tonicity to evoke stimulation (59). Stimulated swallowing is a sign of functional development in behavioral responses for the fetus in view of environmental challenges. Thus, it is an important milestone for early behavioral development in body fluid regulation. Briefly, in mammalian fetuses such as ovine sheep (60), stimulated swallowing appears at pre-term. Swallowing can be significantly increased by both intracellular and extracellular signals, including hypertonicity and Ang II, in the ovine fetus. Thirst responses after birth can be defined as water intake and salt intake for body fluid balance. However, fetuses in utero swallow amniotic fluids that contain water, electrolytes, and other materials. Technically, it is difficult so far to distinguish salt intake or water intake in fetal swallowing. In spite of this, behavioral studies have shown that drinking behavior and thirst responses play a role in fetal body fluid balance, which may be affected by environmental influence during pregnancy, and induce imprinting in fetal origin.

\section{Final considerations}

A number of studies have demonstrated that three major mechanisms, hormonal, renal, and behavioral, are responsible for regulating fluid homeostasis in the adult and they function to some extent in utero. They play an important role in the balance of fluid between the maternal and the fetal bodies. Recently, the fact that in utero development can impact on neonatal and adult health has attracted great interest. For example, recent studies have suggested that maternal high salt intake during pregnancy may have an impact on fetal development, and program adult diseases including hypertension. Therefore, during critical developmental periods, an adverse intrauterine environment might affect fetal hormonal, vascular, and renal systems, which may potentially contribute to the programming of diseases following birth or in adult life.

\section{References}

1. Fitzsimons JT. Angiotensin, thirst, and sodium appetite. Physiol Rev 1998; 78: 583-686.

2. Johnson AK, Thunhorst RL. The neuroendocrinology of thirst and salt appetite: visceral sensory signals and mechanisms of central integration. Front Neuroendocrinol 1997; 18: 292-353.

3. Barker DJ, Bagby SP. Developmental antecedents of cardiovascular disease: a historical perspective. J Am Soc Nephrol 2005; 16: 2537-2544.

4. Yzydorczyk C, Gobeil F Jr, Cambonie G, Lahaie I, Le NL, Samarani $S$, et al. Exaggerated vasomotor response to ANG II in rats with fetal programming of hypertension associated with exposure to a low-protein diet during gestation. Am J Physiol Regul Integr Comp Physiol 2006; 291: R1060R1068.

5. Schutz S, le Moullec JM, Corvol P, Gasc JM. Early expression of all the components of the renin-angiotensin-system in human development. Am J Pathol 1996; 149: 2067-2079.

6. Butkus A, Albiston A, Alcorn D, Giles M, McCausland J, Moritz K, et al. Ontogeny of angiotensin II receptors, types 1 and 2, in ovine mesonephros and metanephros. Kidney Int 1997; 52: 628-636.

7. Wintour EM, Alcom D, Rockell MD. Development and func-

tion of the fetal kidney. In: Brace RA (Editor), Fetus and neonate. Volume IV. Cambridge: Cambridge University Press; 1997.

8. Rawashdeh NM, Rose JC, Rogers MS, Giammattei C, Iskandar SS. Immunocytochemical localization of renin in the developing ovine fetus. Reprod Fertil Dev 1996; 8: 97101.

9. Wang J, Perez FM, Rose JC. Developmental changes in renin-containing cells from the ovine fetal kidney. J Soc Gynecol Investig 1997; 4: 191-196.

10. Moritz K, Koukoulas I, Albiston A, Wintour EM. Angiotensin II infusion to the midgestation ovine fetus: effects on the fetal kidney. Am J Physiol Regul Integr Comp Physiol 2000; 279: R1290-R1297.

11. Xu Z, Shi L, Hu F, White R, Stewart L, Yao J. In utero development of central ANG-stimulated pressor response and hypothalamic fos expression. Brain Res Dev Brain Res 2003; 145: 169-176.

12. Stanley JR, Giammattei CE, Sheikh AU, Green JL, Zehnder $\mathrm{T}$, Rose JC. Effects of chronic infusion of angiotensin II on renin and blood pressure in the late-gestation fetal sheep. Am J Obstet Gynecol 1997; 176: 931-937.

13. Chen K, Carey LC, Valego NK, Liu J, Rose JC. Thyroid 
hormone modulates renin and ANG II receptor expression in fetal sheep. Am J Physiol Regul Integr Comp Physiol 2005; 289: R1006-R1014.

14. Zhang XQ, Varner M, Dizon-Townson D, Song F, Ward K. A molecular variant of angiotensinogen is associated with idiopathic intrauterine growth restriction. Obstet Gynecol 2003; 101: 237-242.

15. Tower $\mathrm{C}$, Baker $\mathrm{P}$. The genetics of fetal growth restriction: Implications for management. Rev Gynaecol Perinat Practice 2006; 6: 99-105.

16. Robillard JE, Page WV, Mathews MS, Schutte BC, Nuyt AM, Segar JL. Differential gene expression and regulation of renal angiotensin II receptor subtypes (AT1 and AT2) during fetal life in sheep. Pediatr Res 1995; 38: 896-904.

17. Hu F, Morrissey P, Yao J, Xu Z. Development of AT(1) and AT(2) receptors in the ovine fetal brain. Brain Res Dev Brain Res 2004; 150: 51-61.

18. Shi L, Yao J, Koos BJ, Xu Z. Induced fetal depressor or pressor responses associated with c-fos by intravenous or intracerebroventricular losartan. Brain Res Dev Brain Res 2004; 153: 53-60.

19. El-Haddad MA, Ismail Y, Gayle D, Ross MG. Central angiotensin II AT1 receptors mediate fetal swallowing and pressor responses in the near-term ovine fetus. Am J Physiol Regul Integr Comp Physiol 2005; 288: R1014-R1020.

20. Carey RM, Jin XH, Siragy HM. Role of the angiotensin AT2 receptor in blood pressure regulation and therapeutic implications. Am J Hypertens 2001; 14: 98S-102S.

21. Wood CE. The function of the fetal pituitary-adrenal system. In: Thorburn GD, Harding R (Editors), Textbook of Fetal Physiology. Oxford: Oxford University Press; 1994. p 351358.

22. Challis JR, Brooks AN. Maturation and activation of hypothalamic-pituitary adrenal function in fetal sheep. Endocr Rev 1989; 10: 182-204.

23. Moritz KM, Boon WC, Wintour EM. Aldosterone secretion by the mid-gestation ovine fetus: role of the AT2 receptor. Mol Cell Endocrinol 1999; 157: 153-160.

24. Mann SE, Nijland MJ, Ross MG. Fetal absorption of intraamniotic aldosterone: effects on urine composition. J Soc Gynecol Investig 1999; 6: 252-257.

25. Benson CA, Wintour EM. The effect of bilateral fetal adrenalectomy on fluid balance in the ovine fetus. J Physiol 1995; 489 (Part 1): 235-241.

26. Cameron VA, Aitken GD, Ellmers LJ, Kennedy MA, Espiner EA. The sites of gene expression of atrial, brain, and C-type natriuretic peptides in mouse fetal development: temporal changes in embryos and placenta. Endocrinology 1996; 137: 817-824.

27. Takahashi T, Allen PD, Izumo S. Expression of A-, B-, and C-type natriuretic peptide genes in failing and developing human ventricles. Correlation with expression of the $\mathrm{Ca}^{(2+)}$ ATPase gene. Circ Res 1992; 71: 9-17.

28. Johnson DD, Tetzke TA, Cheung CY. Gene expression of atrial natriuretic factor in ovine fetal heart during development. J Soc Gynecol Investig 1994; 1: 14-18.

29. Walther T, Schultheiss HP, Tschope C, Stepan H. Natriuretic peptide system in fetal heart and circulation. $J$ Hypertens 2002; 20: 785-791.

30. Cheung CY. Regulation of atrial natriuretic factor secretion and expression in the ovine fetus. Neurosci Biobehav Rev
1995; 19: 159-164.

31. Walther T, Stepan H, Faber R. Dual natriuretic peptide response to volume load in the fetal circulation. Cardiovasc Res 2001; 49: 817-819.

32. Cameron VA, Ellmers LJ. Minireview: natriuretic peptides during development of the fetal heart and circulation. Endocrinology 2003; 144: 2191-2194.

33. Lim AT, Gude NM. Atrial natriuretic factor production by the human placenta. J Clin Endocrinol Metab 1995; 80: 30913093.

34. Dodd A, Kullama LK, Ervin MG, Leake RD, Ross MG. Ontogeny of ovine fetal renal atrial natriuretic factor receptors. Life Sci 1994; 54: 1101-1107.

35. Perreault T, Baribeau J, Gutkowska J. ANF system in the newborn piglet pulmonary vessels. J Cardiovasc Pharmacol 1997; 29: 740-746.

36. $\mathrm{Xu} \mathrm{H}, \mathrm{Hu} X Y, \mathrm{Wu} L$, Zhou JN. Neurotensin expressing neurons developed earlier than vasoactive intestinal polypeptide and vasopressin expressing neurons in the human suprachiasmatic nucleus. Neurosci Lett 2003; 335: 175178.

37. Lipari EF, Lipari D, Gerbino A, Di Liberto D, Bellafiore M, Catalano $\mathrm{M}$, et al. The hypothalamic magnocellular neurosecretory system in developing rats. Eur J Histochem 2001; 45: 163-168.

38. Hansenne I, Rasier G, Pequeux C, Brilot F, Renard C, Breton $\mathrm{C}$, et al. Ontogenesis and functional aspects of oxytocin and vasopressin gene expression in the thymus network. J Neuroimmunol 2005; 158: 67-75.

39. Martinez A, Farr A, Vos MD, Cuttitta F, Treston AM. Peptide-amidating enzymes are expressed in the stellate epithelial cells of the thymic medulla. J Histochem Cytochem 1998; 46: 661-668.

40. Arnauld E, Wattiaux JP, Arsaut J, Rostene W, Vincent JD. Alterations in vasopressin and oxytocin messenger RNA in the rat supraoptic nucleus during dehydration-rehydration evaluated by in situ hybridization and northern blotting. Neurosci Lett 1993; 149: 177-181.

41. Ramirez BA, Wang S, Kallichanda N, Ross MG. Chronic in utero plasma hyperosmolality alters hypothalamic arginine vasopressin synthesis and pituitary arginine vasopressin content in newborn lambs. Am J Obstet Gynecol 2002; 187: 191-196.

42. Laszlo FA, Laszlo F Jr, De Wied D. Pharmacology and clinical perspectives of vasopressin antagonists. Pharmacol Rev 1991; 43: 73-108.

43. McCann SM, Antunes-Rodrigues J, Jankowski M, Gutkowska J. Oxytocin, vasopressin and atrial natriuretic peptide control body fluid homeostasis by action on their receptors in brain, cardiovascular system and kidney. Prog Brain Res 2002; 139: 309-328.

44. Nielsen S, Chou CL, Marples D, Christensen El, Kishore BK, Knepper MA. Vasopressin increases water permeability of kidney collecting duct by inducing translocation of aquaporin-CD water channels to plasma membrane. Proc Natl Acad Sci U S A 1995; 92: 1013-1017.

45. Albuquerque CA, Nijland MJ, Ross MG. Mechanism of arginine vasopressin suppression of ovine fetal lung fluid secretion: lack of V2-receptor effect. J Matern Fetal Med 1998; 7: 177-182.

46. Varlinskaya El, Petrov ES, Robinson SR, Smotherman WP. 
Behavioral effects of centrally administered arginine vasopressin in the rat fetus. Behav Neurosci 1994; 108: 395409.

47. Xu Z, Hu F, Shi L, Sun W, Wu J, Morrissey P, et al. Angiotensin-induced vasopressin release and activation of hypothalamic neuron in pre-term fetuses. Peptides 2005; 26: 307-314

48. Jensen E, Wood CE, Keller-Wood M. Alterations in maternal corticosteroid levels influence fetal urine and lung liquid production. J Soc Gynecol Investig 2003; 10: 480-489.

49. Tena JJ, Neto A, de la Calle-Mustienes E, Bras-Pereira C, Casares F, Gomez-Skarmeta JL. Odd-skipped genes encode repressors that control kidney development. Dev Biol 2007; 301: 518-531.

50. Woolf AS, Price KL, Scambler PJ, Winyard PJ. Evolving concepts in human renal dysplasia. J Am Soc Nephrol 2004; 15: 998-1007.

51. Guignard JP. Renal morphogenesis and development of renal function. In: Taeusch HW, Ballard RA, Gleason CA (Editors), Avery's diseases of the newborn. Philadelphia: Elsevier Saunders; 2005. p 1258-1259.

52. Beck JC, Lipkowitz MS, Abramson RG. Characterization of the fetal glucose transporter in rabbit kidney. Comparison with the adult brush border electrogenic $\mathrm{Na}^{+}$-glucose symporter. J Clin Invest 1988; 82: 379-387.

53. Igarashi P, Vanden Heuvel GB, Payne JA, Forbush B III.
Cloning, embryonic expression, and alternative splicing of a murine kidney-specific Na-K-Cl cotransporter. Am J Physiol 1995; 269: F405-F418.

54. Quigley R, Mulder J, Baum M. Ontogeny of water transport in the rabbit proximal tubule. Pediatr Nephrol 2003; 18: 1089-1094

55. Bonilla-Felix M, Jiang W. Aquaporin-2 in the immature rat: expression, regulation, and trafficking. J Am Soc Nephrol 1997; 8: 1502-1509.

56. Lumbers ER. Functions of the renin-angiotensin system during development. Clin Exp Pharmacol Physiol 1995; 22: 499-505.

57. Bonilla-Felix M. Development of water transport in the collecting duct. Am J Physiol Renal Physiol 2004; 287: F1093F1101.

58. El-Haddad MA, Chao CR, Ross MG. N-methyl-D-aspartate glutamate receptor mediates spontaneous and angiotensin II-stimulated ovine fetal swallowing. J Soc Gynecol Investig 2005; 12: 504-509.

59. Xu Z, Nijland MJ, Ross MG. Plasma osmolality dipsogenic thresholds and c-fos expression in the near-term ovine fetus. Pediatr Res 2001; 49: 678-685.

60. Xu Z, Glenda C, Day L, Yao J, Ross MG. Central angiotensin induction of fetal brain c-fos expression and swallowing activity. Am J Physiol Regul Integr Comp Physiol 2001; 280: R1837-R1843. 